\title{
Optimasi Suhu Aktivasi Proses Pembuatan Arang Aktif Limbah Tulang Kambing
}

\author{
Sari Wardani ${ }^{1 *}$, Rina Mirdayanti ${ }^{2}$ \\ ${ }^{1}$ Fakultas Pertanian Universitas Abulyatama \\ ${ }^{2}$ FKIP Fisika Universitas Abulyatama \\ Jl. Blang Bintang Lama Km 8,5, Lampoh Keude Aceh Besar \\ *Korensponden email: sariwardani_peternakan@abulyatama.ac.id
}

Diterima: 28 Juni 2019

Disetujui: 8 Juli 2019

\begin{abstract}
Livestock waste, such as bone, has always been ineffectively exploited. Bones contain organic compounds that can be further processed into usable products such as charcoal and activated charcoal. This research, therefore, aims to identify the optimum temperature conditions suitable for the manufacturing process of activated charcoal from goat bone waste using thermal activation. The study uses a two-stage process which is carbonization and thermal activation. Activation temperatures used in the process were at a temperature of $500{ }^{\circ} \mathrm{C}, 600$ ${ }^{\circ} \mathrm{C}$ and $700{ }^{\circ} \mathrm{C}$ for three hours. The results of the characteristics of activated charcoal thermally produced in this research met the Indonesian National Standard 06-3730-1995 about technical activated charcoal, and the optimum conditions were at an activation temperature of $500{ }^{\circ} \mathrm{C}$. These characteristics include the values of the water content at $1.210 \%$, ash content at $2.034 \%$, absorption of iodine $926 \mathrm{mg} / \mathrm{g}$, volatile matter of $0.434 \%$ and fixed carbon of $96.616 \%$.
\end{abstract}

Keywords: activation temperature, activated charcoal, bone wastes goat

\begin{abstract}
Abstrak
Limbah hasil peternakan selama ini belum termanfaatkan dengan baik, seperti limbah tulang. Tulang mengandung senyawa organik yang jika diproses lebih lanjut dapat menghasilkan produk berupa arang dan arang aktif. Tujuan penelitian adalah untuk mengidentifikasi kondisi suhu optimum proses pembuatan arang aktif berbahan baku limbah tulang kambing yang teraktivasi secara thermal. Penelitian ini menggunakan dua tahapan proses yaitu karbonisasi dan aktivasi secara thermal. Suhu aktivasi yang digunakan adalah pada suhu $500{ }^{\circ} \mathrm{C}, 600{ }^{\circ} \mathrm{C}$ dan $700{ }^{\circ} \mathrm{C}$ selama tiga jam. Hasil karakteristik arang aktif yang diaktivasi secara thermal pada penelitian ini telah memenuhi Standar Nasional Indonesia 06-3730-1995 tentang arang aktif teknis, dengan kondisi optimum berada pada suhu aktivasi $500{ }^{\circ} \mathrm{C}$ dengan karakteristik arang aktif terbaik pada nilai kadar air 1,210 \%, kadar abu 2,034 \%, daya serap iodium $926 \mathrm{mg} / \mathrm{g}$, zat mudah menguap 0,434 \% dan kadar karbon $96,616 \%$.
\end{abstract}

\section{Pendahuluan}

Kambing termasuk golongan ternak ruminansia yang banyak diternakan dikalangan peternak, hal ini didasari oleh permintaan akan olahan daging kambing yang semakin meningkat setiap harinya. Data Statistik Peternakan dan Kesehatan Hewan Tahun 2018 menyatakan bahwa populasi ternak kambing secara nasional mengalami peningkatan sebesar 1,94 persen di tahun 2017 dengan jumlah populasi sebesar 18,2 juta ekor. Populasi ternak kambing khususnya Provinsi Aceh juga mengalami peningkatan pada tahun 2018 sebesar 658.613 ekor jika dibandingkan pada tahun ternak 2017 sebesar 615.526 ekor. Peningkatan populasi ternak kambing akan berdampak terhadap meningkatnya limbah dari hasil olahan hewan ternak tersebut. Salah satu limbah hasil pemotongan dan olahan ternak kambing adalah tulang. Sampai saat ini pemanfaatan limbah tulang kambing belum secara optimal (Juliasti, Legowo, \& Pramono, 2015), sehingga diperlukan teknologi yang dapat mengolah limbah tulang menjadi produk yang bermanfaat dan bernilai jual tinggi.

Tulang kambing mengandung senyawa anorganik sebesar $\pm 69 \%$, senyawa organik $\pm 22 \%$ dan air 9 $\%$. Senyawa organik mengadung $90 \%$ kolagen, yang dapat diproses sebagai bahan baku pembuatan arang tulang. Kandungan karbon yang terdapat pada arang aktif mencapai $85-95 \%$ yang diperoleh dari hasil 
pengolahan materi yang banyak mengandung unsur karbon yang di proses menggunakan temperatur yang tinggi (Chand dkk., 2005). Arang aktif merupakan produk yang bernilai jual tinggi, hal ini didasari dari kegunaan arang aktif yang sangat luas. Arang dan arang aktif yang diproses lebih lanjut dapat dipergunakan sebagai bahan pengendali pencemaran bahan agrokimia dan pencemaran logam berat pada lahan pertanian dengan menggunakan metode ameliorasi, sehingga limbah hasil pertanian dapat dimanfaatkan secara optimal (E.S. Harsanti, Asep Nugraha Ardiwinata, 2011). Arang aktif diproduksi dari bahan dasar organik seperti tempurung kelapa, kulit inti sawit, serpihan kayu, tulang binatang, tongkol jagung, sekam padi dan sebagainya (Arsad, 2017; Mohammad-Khah \& Ansari, 2009). Arang aktif dapat diaplikasikan sebagai pemucat atau sebagai penyerap uap, pada teknologi adsorpsi arang aktif mampu menyerap logam berat pada industri obatobatan, industri makanan, industri minuman keras, industri kimia perminyakan, budidaya udang, industri gula, pemurnian gas, katalisator serta pada proses pengolahan pupuk (Arsad \& Hamdi, 2010). Arang hewan juga dikenal sebagai tulang hitam, arang tulang atau abaiser, adalah bahan granular yang diproduksi oleh arang tulang hewan. Tulang hewan adalah bagian dari komposit yang membentuk tubuh hewan, pada dasarnya memberi bentuk dan dukungan untuk hewan. Tulang hewan mengandung sekitar 10\% karbon, sisanya adalah kalsium dan magnesium $(80 \%)$ dan bahan anorganik lainnya (Mohammed, Aboje, Auta, \& Jibril, 2012).

Penelitian - penelitian terkini membuktikan bahwa tulang hewan dapat diproses menjadi bahan dasar produk arang aktif. Arang dari tulang domba yang teraktivasi seng klorida dapat diaplikasikan untuk mengadsorpsi merkuri (II) dengan volume pori sebesar $83,98 \mathrm{~m} / \mathrm{g}$ (Dawlet, dkk, 2013). Arang tulang ayam, anjing, kambing dan sapi yang diaktivasi menggunakan hidrogen klorida $2 \mathrm{M}$ mampu mengadsopsi warna minyak sawit, hasil penelitian menunjukkan tingkat penyerapan tulang ayam sebesar 275 , tulang kambing 268 , tulang anjing 261 dan tulang sapi 220 jika dibandingkan dengan warna minyak sebelum pemutihan sebesar 279 (Mohammed dkk., 2012). Arang tulang sapi teraktivasi natrium karbonat, mampu mengadsopsi logam tembaga sebesar $99,65 \%$ (Previanti, dkk, 2017). Arang tulang kambing yang teraktivasi asam sulfat $3 \mathrm{~N}$ mampu menyerap Iod 983 mg/g (Wardani \& Rosa, 2018). Arang tulang sapi digunakan sebagai adsorben untuk menghilangkan kromium heksavalen di dalam air (Ghanizadeh, dkk,
2012). Tujuan penelitian ini adalah untuk mengurangi cemaran yang disebabkan oleh limbah tulang kambing dengan mengolah limbah tulang kambing menjadi arang aktif yang diaktivasi secara thermal sehingga di hasilkan produk arang aktif yang mempunyai karakteristik terbaik serta memenuhi SNI No. 063730-1995 tentang arang aktif teknis.

\section{Metode Penelitian}

Penelitian menggunakan limbah tulang kambing sebagai bahan dasar pembuatan arang aktif yang dikumpulkan dari rumah makan olahan daging kambing dan rumah pemotongan hewan pada kabupaten Aceh Besar, adapun bahan penelitian lainnya terdiri dari aquadest, kertas saring whatman, larutan iodine dengan normalitas 0,1, Natrium Thiosulfat dengan normalitas 0,1 dan Indikator amilum 1 persen. Sedangkan peralatan yang terdiri dari gelas beker (pyrex), gelas ukur (pyrex), batang pengaduk, corong gelas, pipet tetes, pipet ukur, hot plate magnetic stirrer, oven, furnace, desikator, timbangan, ayakan mesh, masker, sarung tangan, buret, statif dan centrifuge. Penelitian ini menggunakan dua variabel yaitu variabel tetap yaitu berat arang tulang kambing (10 gr), waktu karbonisasi 20 menit, suhu karbonisasi $700{ }^{\circ} \mathrm{C}$, waktu aktivasi tiga jam, ukuran mesh 100 dan variabel berubah adalah suhu aktivasi pada 500 ${ }^{\circ} \mathrm{C}, 600{ }^{\circ} \mathrm{C}$ dan $700{ }^{\circ} \mathrm{C}$. Limbah tulang kambing yang telah dikumpulkan kemudian di proses untuk menjadi arang aktif yang terdiri dari preparasi bahan baku, karbonisasi tulang, aktivasi arang tulang serta uji karakteristik arang aktif tulang kambing.

\subsection{Preparasi Limbah Tulang Kambing}

Limbah tulang kambing yang sudah dikumpulkan dibersihkan dari daging yang masih melekat, dicuci, dijemur dibawah sinar matahari hingga kering selanjutkan tulang kambing yang sudah kering di oven yang berfungsi untuk mengurangi kandungan air yang masih tersisa didalam tulang.

\subsection{Proses Karbonisasi}

Karbonisasi bertujuan untuk menguraikan selulosa organik sehingga dihasilkan unsur karbon yang disertai dengan penghilangan unsur - unsur non-karbon. Proses karbonisasi terjadi pada suhu $600{ }^{\circ} \mathrm{C}-800{ }^{\circ} \mathrm{C}$ (Arsad \& Hamdi, 2010; Meisrilestari, Khomaini, \& Wijayanti, 2013). Tulang kambing yang telah dibersihkan dari daging yang melekat kemudian dikeringkan selanjutnya ditimbang sebanyak $0,5 \mathrm{~kg}$ untuk dilakukan pengecilan ukuran hingga berukuran $3 \mathrm{~cm}$. Proses karbonisasi berlangsung pada suhu $700{ }^{\circ} \mathrm{C}$. 


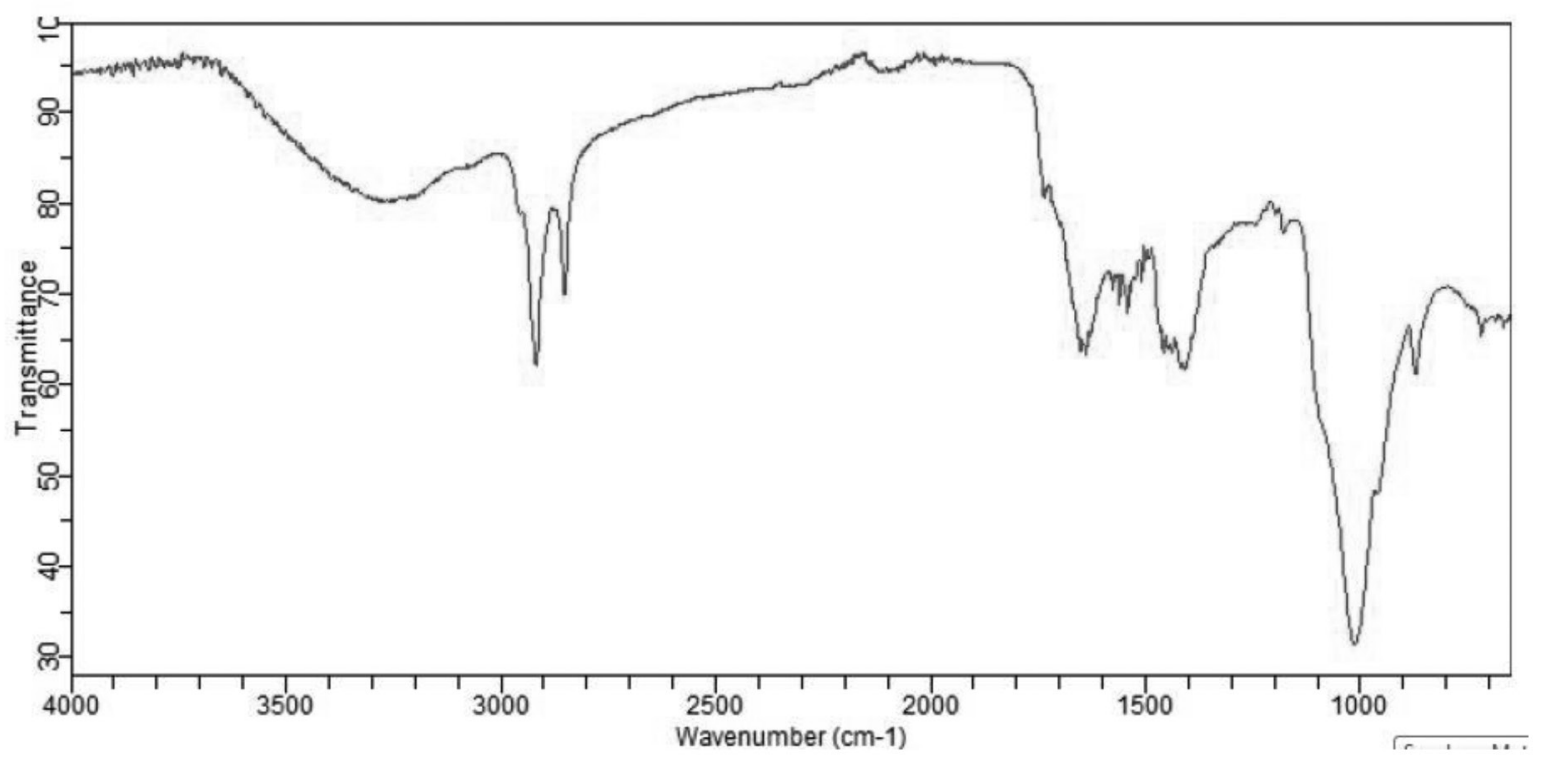

Gambar 1. Hasil FT-IR arang tulang kambing

\subsection{Proses Aktivasi}

Arang tulang kambing diaktivasi menggunakan enam perlakuan. Arang hasil karbonisasi selanjutnya dihaluskan sampai lolos pada saringan 100 mesh. Proses aktivasi menggunakan furnace pada suhu 500 ${ }^{\circ} \mathrm{C}, 600{ }^{\circ} \mathrm{C}$ dan $700{ }^{\circ} \mathrm{C}$ dengan waktu aktivasi 3 jam.

\subsection{Karakteristik Arang Aktif Tulang Kambing} Arang aktif selanjutnya dilakukan pengujian karakteristik yaitu kandungan kadar air, kadar abu, kemampuan daya serap iodium, zat menguap, kandungan karbon dan gugus fungsi arang. Prosedur analisa karakteristik arang aktif mengikuti proses pengujian SNI 06-3730-1995 tentang arang aktif teknis meliputi:

\section{Uji Kadar Air}

Menimbang kertas saring kosong

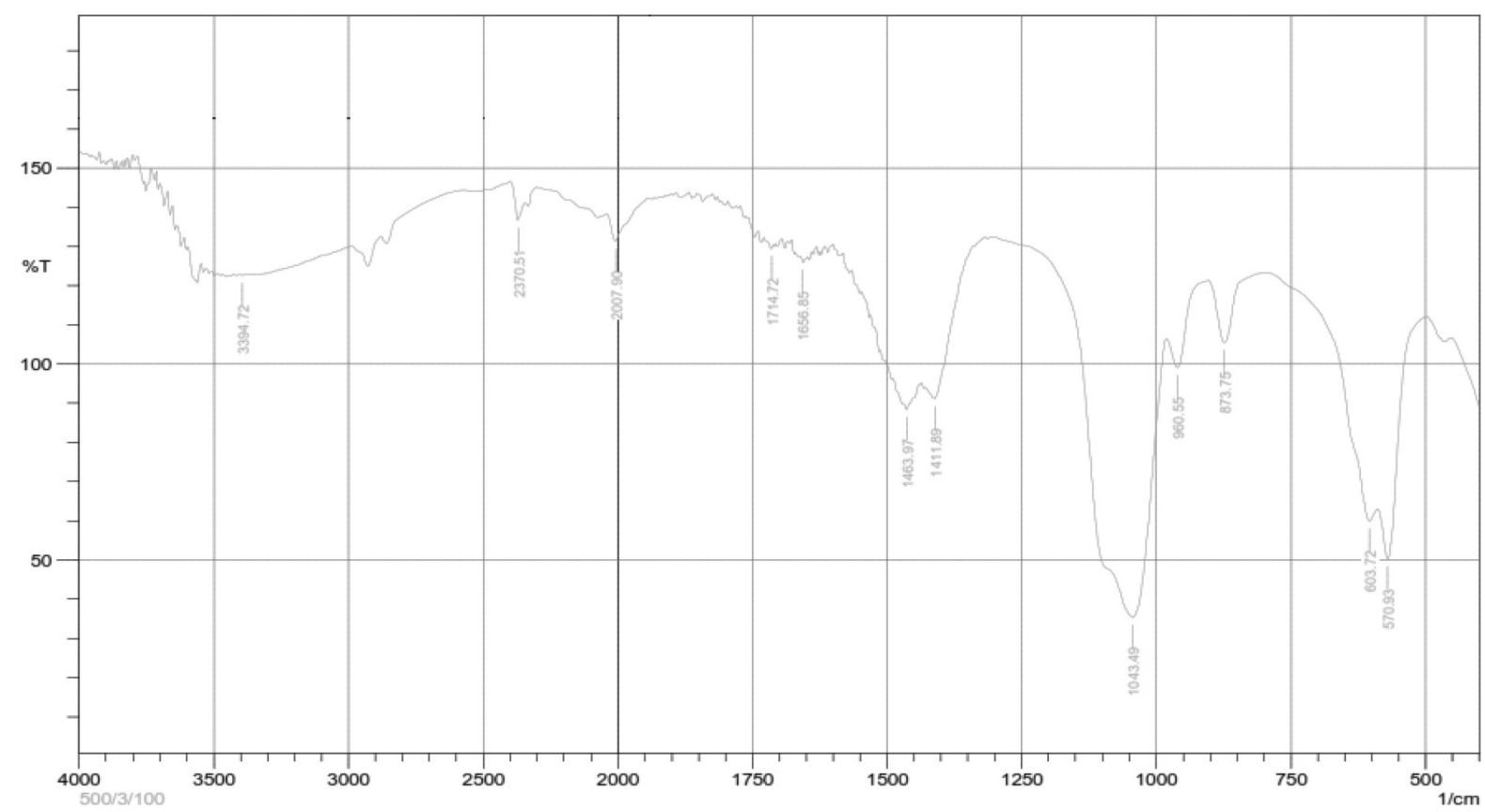

Gambar 2. Hasil FT-IR arang tulang kambing teraktivasi $500{ }^{\circ} \mathrm{C}$ 


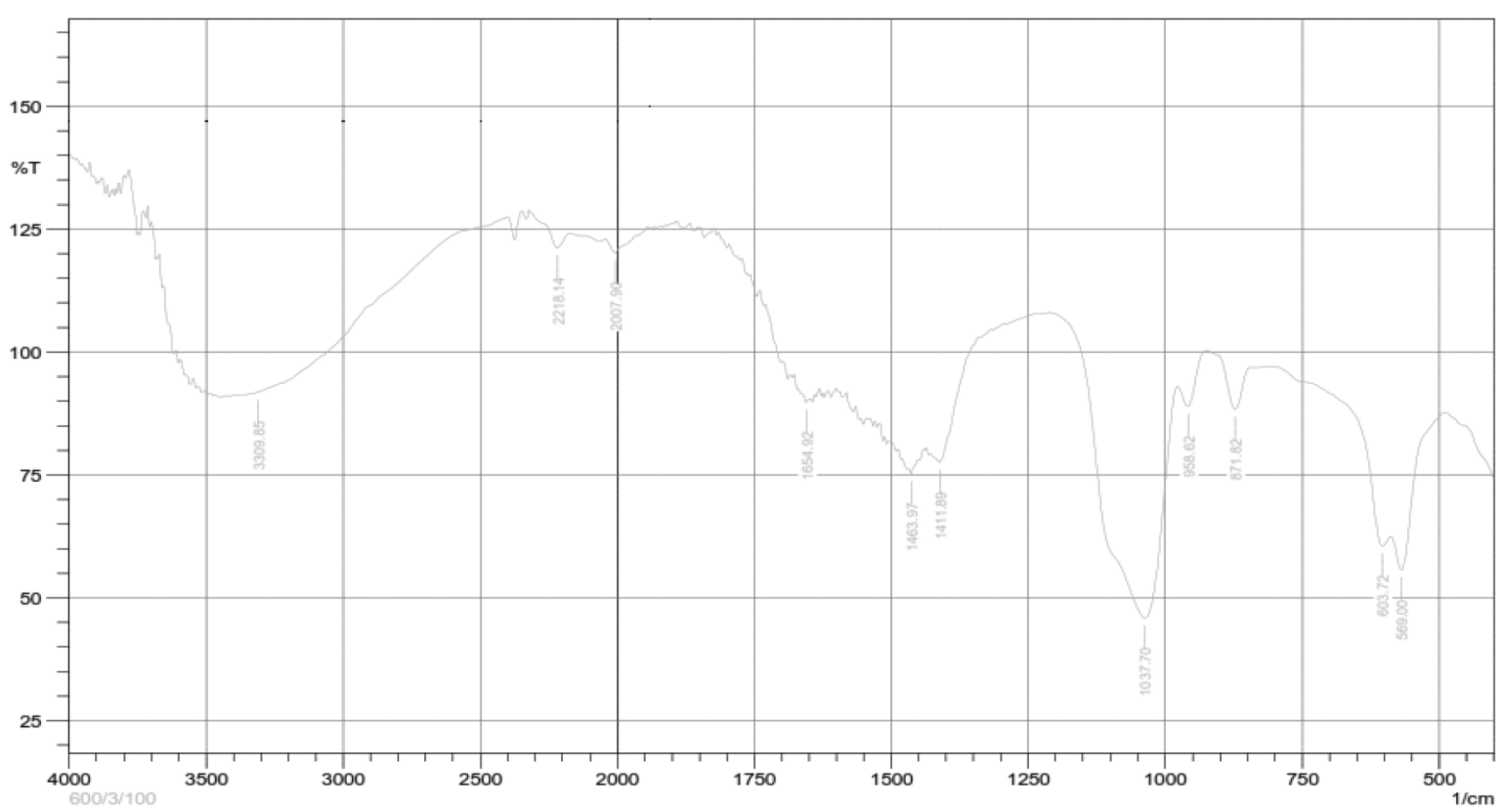

Gambar 3. Hasil FT-IR arang tulang kambing teraktivasi $600{ }^{\circ} \mathrm{C}$

kemudian menambahkan sebanyak satu gram arang aktif kedalam kertas saring selanjutnya dioven selama tiga jam menggunakan suhu $105{ }^{\circ} \mathrm{C}$, selanjutnya sampel dinginkan dalam eksikator kemudian ditimbang untuk mendapatkan kadar air arang aktif tersebut. Perhitungan kadar air mengikuti persamaan berikut ini:

$$
\begin{aligned}
& \text { Kadar air }(\%)=\underline{\text { Berat awal }- \text { Berat akhir }} \\
& \%
\end{aligned}
$$

\section{Uji Kadar Abu}

Menimbang cawan porselin kosong dan mencatatnya selajutnya menambahkan sebanyak satu gram sampel kedalam cawan porselin tersebut. Cawan yang berisi arang aktif kemudian dipanaskan dalam furnace sampai menjadi abu pada suhu $750{ }^{\circ} \mathrm{C}$ selama satu jam, arang yang telah diabukan kemudian didinginkan didalam desikator dan ditimbang agar diketahui nilai kadar abunya. Perhitungan kadar abu mengikuti persamaan berikut ini:

Kadar Abu $=\frac{\text { Berat abu total }}{\text { Berat contoh awal }} \times 10$

3. Uji Kadar Zat Menguap

Menimbang cawan porselin kosong kemudian masukkan sebanyak satu gram sampel dan timbang kembali selanjutnya menambahkan arang aktif ke dalam porselin dan dipanaskan dalam furnace pada suhu $900{ }^{\circ} \mathrm{C}$ selama 7 menit, selanjutnya keluarkan porselin dari furnace dan ditimbang. Perhitungan kadar zat menguap mengikuti persamaan berikut ini:

$\mathrm{VM}=\frac{M_{2}-M_{3}}{M_{2}-M_{1}} \times 100-\mathrm{M}$.

Dimana: VM kandungan zat terbang (\%), $\mathrm{M}_{1}$ (berat porselin), $\mathrm{M}_{2}$ (berat porselin dan contoh sebelum pemanasan), $M_{3}$ (berat porselin dan sampel setelah pemanasan) dan $\mathrm{M}$ (kandungan kadar air).

4. Uji Kadar Karbon

Kadar karbon adalah dengan melakukan penjumlahan kadar air ditambah kadar abu dan kadar zat terbang kemudian di kurangi seratus. Perhitungan kadar karbon mengikuti persamaan berikut ini:

Kadar Karbon $=100-($ K Air + K Abu + VM $)$ (dalam \%)

5. Uji Penyerapan Iodium

Uji penyerapan iodium dimulai dengan memanaskan arang aktif sebanyak satu gram pada suhu $105{ }^{\circ} \mathrm{C}$ dengan waktu satu jam didalam oven. Selanjutnya ditimbang arang aktif sebanyak 0,5 gram kemudian ditambahkan larutan iodium dengan Normalitas 0,1 sebanyak 50 dan dilakukan pengadukan menggunakan selama 15 menit selanjutnya di sentrifugal untuk mendapatkan filtrat, proses sentrifugal berlangsung selama 
15 menit. Filtrat yang didapat diambil $10 \mathrm{~mL}$ yang akan dititrasi dengan menggunakan larutan natrium tiosulfat $0,1 \quad \mathrm{~N}$. Titrasi dilakukan sampai filtrat berwarna kuning samar, kemudian tambahkan sebanyak $1 \mathrm{ml}$ larutan amilum pada konsetrasi 1\%. Proses titrasi dilakukan secara terus menerus sampai warna biru hilang. Perhitungan uji penyerapan iodium mengikuti persamaan berikut:

Daya serap $\left(\frac{\mathrm{mg}}{\mathrm{g}}\right)=\frac{(\mathrm{V} 1 N 1-V 2 N 2) \times 12,69 \times 5}{W}$

Dimana: $\mathrm{V}_{1}$ (larutan iodium yang dianalisa, $\mathrm{mL}$ ), $\mathrm{V}_{2}$ (larutan natrium tiosulfat yang dibutuhkan ( $\mathrm{mL}$ ), $\mathrm{N}_{1}$ (normalitas iodium), $\mathrm{N}_{2}$ (normalitas natrium tiosulfat), W (berat sampel, gr).

6. Uji Analisa Gugus Fungsi Arang dan Arang Aktif

Analisa gugus fungsi arang dan arang aktif menggunakan alat FT-IR dengan spesifikasi Agilent Techologies Cary 630.

\section{Hasil Dan Pembahasan}

\subsection{Karakteristik Arang Tulang Kambing}

Proses pembuatan arang aktif tulang kambing dimulai dengan proses penjemuran tulang dibawah sinar matahari yang berfungsi untuk mengurangi kandungan air yang terdapat di dalam tulang kambing.
Setelah proses pengeringan tulang kambing selesai kemudian dilanjutkan dengan proses karbonisasi pada suhu $700{ }^{\circ} \mathrm{C}$ sehingga didapatkan arang tulang kambing. Proses karbonisasi bertujuan untuk menghilangkan unsur oksigen dan hidrogen yang terkandung di dalam karbon agar dapat membentuk kerangka karbon yang baru dengan tingkat kemurnian yang tinggi (Mizwar, 2018). Karakteristik arang tulang kambing ditampilkan pada Tabel 1.

\subsection{Karakteristik Arang Aktif Tulang Kambing}

Analisa karakteristik arang aktif dilakukan untuk mempelajari sifat dasar pada arang aktif yang terdiri dari kadar air, kadar abu, kadar zat menguap, kadar karbon dan penyerapan iodium. Tabel 2 memperlihatkan karakteristik arang aktif tulang kambing.

Analisa kadar air dilakukan untuk mengetahui kemampuan menyerap molekul air yang terdapat pada arang aktif. Kandungan kadar air dipengaruhi oleh jumlah uap di udara dan lama proses pendinginan (ElHendawy, 2003). Tabel 2 memperlihatkan pada suhu $600{ }^{\circ} \mathrm{C}$ kadar air tulang kambing semakin meningkat seiring dengan penambahan suhu aktivasi. Hasil penelitian ini juga pernah dialami pada pembuatan karbon aktif berbahan tempurung kelapa, dimana semakin meningkat suhu aktivasi maka nilai kadar air semakin meningkat, hal ini disebabkan semakin lama waktu yang dibutuhkan maka pori - pori arang akan semakin terbuka, sehingga ketika proses pemindahan

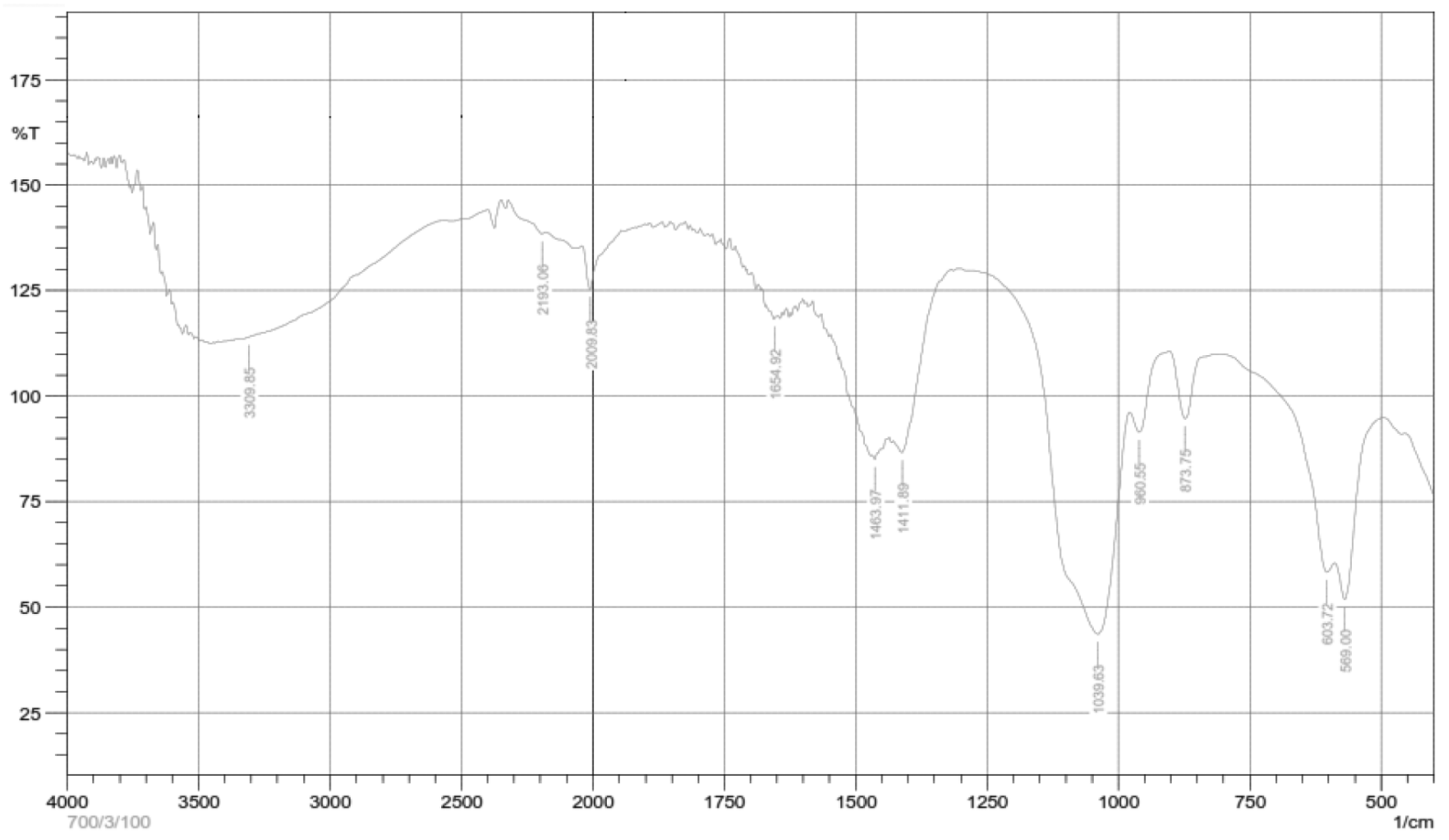

Gambar 4. Hasil FT-IR arang tulang kambing teraktivasi $700{ }^{\circ} \mathrm{C}$ 
Tabel 1. Karakteristik arang aktif tulang kambing

\begin{tabular}{lccc}
\hline \multirow{2}{*}{ Karakteristik } & \multicolumn{3}{c}{ Suhu Aktivasi } \\
\cline { 2 - 4 } & $500^{\circ} \mathrm{C}$ & $600^{\circ} \mathrm{C}$ & $700{ }^{\circ} \mathrm{C}$ \\
\hline Kadar Air (\%) & 1,210 & 1,738 & 1,610 \\
Kadar Abu (\%) & 2,034 & 8,108 & 4,124 \\
Kadar Zat Menguap (\%) & 0,434 & 8,296 & 2,797 \\
Kadar Karbon (\%) & 96,616 & 88,794 & 94,744 \\
Penyerapan Iodium (mg/g) & 926 & 806 & 768 \\
\hline
\end{tabular}

arang aktif ke desikator terjadi kontak langsung antara arang yang bersifat hidroskopis dengan udara yang berakibat arang banyak menyerap kandungan air (Hartanto \& Ratnawati, 2010). Hasil penelitian pada pembuatan arang aktif dari tulang sapi juga mendapatkan bahwa semakin meningkat temperatur aktivasi maka kadar air akan mengalami penurunan (Previanti dkk., 2017). Secara keseluruhan kadar air yang diperoleh dalam penelitian telah sesuai dengan SNI 06-3730-1995.

Penentuan kandungan oksida logam di dalam arang dapat ditentukan dari nilai kadar abu arang tersebut. Kadar abu sangat ditentukan oleh suhu aktivasi, semakin tinggi perlakuan suhu waktu aktivasi maka akan meningkatkan nilai kadar abu (Sudrajat, 2005). Penyumbatan pori - pori pada arang dapat diakibatkan dari tingginya nilai kadar abu yang berlebihan, sehingga luas permukaan arang menjadi sedikit. Hasil penelitian pada proses pembuatan arang aktif berbahan baku tulang sapi juga mendapatkan nilai kadar abu meningkat sejalan dengan meningkatnya suhu aktivasi (Previanti dkk., 2017). Kadar abu ratarata arang aktif tulang kambing berkisar antara 2,034 - 8,108 \%, hasil yang diperoleh memenuhi SNI 063730-1995 tentang arang aktif teknis dengan nilai maksimal kadar abu adalah $10 \%$.

Penentuan kadar zat mudah menguap untuk menunjukkan presentase jumlah zat - zat terbang yang terkandung di dalam arang aktif seperti $\mathrm{H}_{2}, \mathrm{CO}$, $\mathrm{CH}_{4}, \mathrm{CO}_{2}$ dan $\mathrm{H}_{2} \mathrm{O}$ (Mody, 2014). Apabila arang aktif banyak menggandung senyawa non karbon yang ditandai dengan tingginya kadar zat yang mudah menguap maka dapat disimpulkan bahwa kemampuan daya serap arang aktif tersebut sangat rendah dan memiliki kualitas yang kurang baik (Hendra, 2007). Semakin tinggi suhu aktivasi maka akan mengurangi persentase kadar kadar zat mudah menguap dalam arang aktif (Siahaan, Hutapea, \& Hasibuan, 2013). Hasil rata - rata yang diperoleh berkisar antara 2,797 - 9,788 \%, nilai ini masih memenuhi SNI 06-37301995 tentang arang aktif teknis dengan nilai maksimal kadar zat mudah menguap adalah $25 \%$. Hasil penelitian ini juga diterjadi pada proses pembuatan arang aktif berbahan baku tempurung biji nyamplung dan sekam padi, dimana dengan meningkatnya temperatur aktivasi maka nilai kadar zat mudah menguap mengalami penurunan (Siahaan dkk., 2013; Wibowo, Syafii, \& Pari, 2016).

Jumlah karbon murni dalam suatu arang aktif dapat ditentukan dari persentase kadar karbon arang aktif tersebut. Temperatur aktivasi yang tinggi dapat mempengaruhi persentase kadar karbon suatu arang. Tinggi rendahkan kandungan kadar karbon akan mempengaruhi daya serap arang aktif pada proses adsorpsi. Semakin tinggi nilai kadar karbon maka semakin baik kualitas arang aktif yang dihasilkan dikarenakan jumlah pori - pori yang semakin banyak. Hasil penelitian memperlihatkan kadar karbon arang aktif tulang kambing berkisar antara 88,744 \% - 96,616 \%. Hasil ini memenuhi standar yang ditetapkan untuk arang aktif teknis SNI 06-3730-1995. Kemampuan daya serap arang aktif terhadap penyerapan iodium berfungsi untuk melihat kemampuan arang aktif sebagai adsorbat. Semakin tinggi kemampuan arang aktif dalam menyerap iodium maka kualitas arang aktif yang dihasilkan semakin berkualitas. Hasil penelitian terhadap kemampuan arang aktif tulang kambing dalam menyerap iodium telah memenuhi SNI 06-3730-1995 yang berkisar antara $768 \mathrm{mg} / \mathrm{g}-$ $926 \mathrm{mg} / \mathrm{g}$.

Identifikasi gugus fungsi arang dan arang aktif tulang kambing berfungsi untuk melihat perubahan gugus fungsi arang setelah dilakukan perlakuan pada variasi suhu aktivasi. Spektrum FT-IR pada arang memperlihatkan pita serapan berada di bilangan $3205 \mathrm{~cm}^{-1}$ mengandung gugus $\mathrm{O}-\mathrm{H}$. Kemudian pita serapan juga berada di gelombang $2917 \mathrm{~cm}^{-1}$ dan $2851 \mathrm{~cm}^{-1}$ yang merupakan gugus $\mathrm{C}-\mathrm{H}$ alifatik. Pada gelombang $2141 \mathrm{~cm}^{-1}$ arang berada gugus $\mathrm{C}-$ C, selanjutnya terdapat pita serapan pada gelombang $1637 \mathrm{~cm}^{-1}$ yang merupakan gugus $\mathrm{C}=\mathrm{C}$. Pita serapan juga menunjukkan adanya gugus $\mathrm{NO}_{2}$ yang terdapat pada gelombang $1541 \mathrm{~cm}^{-1}$ dan $1508 \mathrm{~cm}^{-1}$. Spektrum FT-IR juga menunjukkan adanya pita gelombang pada $960 \mathrm{~cm}^{-1}, 871 \mathrm{~cm}^{-1}, 717 \mathrm{~cm}^{-1}, 1197 \mathrm{~cm}^{-1}$ dan $1178 \mathrm{~cm}^{-1}$ yang memperlihatkan bahwa arang juga mempunyai 
gugus $\mathrm{C}-\mathrm{H}, \mathrm{C}-\mathrm{N}$ dan $\mathrm{C}-\mathrm{O}$. Secara keseluruhan arang tulang kambing banyak mengandung unsur karbon yang dapat di manfaatkan sebagai bahan baku arang aktif. Hasil FT-IR arang tulang kambing di perlihatkan pada Gambar 1.

Arang aktif yang diaktivasi pada suhu $500^{\circ}$ C menunjukkan perubahan spektrum FT-IR jika dibandingkan dengan spektrum pada arang sebelum diaktivasi. Gugus fungsi setelah arang diaktivasi pada suhu $500^{\circ} \mathrm{C}$ selama 3 jam menghasilkan gugus fungsi $\mathrm{C}-\mathrm{H}$ di gelombang $873,75 \mathrm{~cm}^{-1}$ dan $960,55 \mathrm{~cm}^{-1}$ yang termasuk kedalam senyawa alkena dengan intensitas yang kuat. Gugus fungsi lainnya di perlihatkan pada gelombang $1411,89 \mathrm{~cm}^{-1}$ dan 1463,97 $\mathrm{cm}^{-1}$ yaitu gusus $\mathrm{C}-\mathrm{H}$ dengan intensitas yang kuat berupa senyawa alkana. Spektrum FT-IR juga menghasilkan gugus fungsi $\mathrm{C}=\mathrm{C}, \mathrm{C}=\mathrm{O}$ dan $\mathrm{O}-\mathrm{H}$ masing - masing pada gelombang $1656,85 \mathrm{~cm}^{-1}, 1714,72 \mathrm{~cm}^{-1}, 2007,9 \mathrm{~cm}^{-1}$, $2370,51 \mathrm{~cm}^{-1}$ dan $3394,72 \mathrm{~cm}^{-1}$. Secara keseluruhan gugus fungsi arang aktif yang diaktivasi pada suhu $500^{\circ} \mathrm{C}$ dengan intensitas yang tinggi berada pada gugus fungsi $\mathrm{O}-\mathrm{H}$ dengan intensitas 136,7. Hasil FTIR untuk arang aktif yang diaktivasi pada suhu $500^{\circ} \mathrm{C}$ di perlihatkan pada Gambar 2 .

Proses aktivasi menggunakan suhu $600^{\circ} \mathrm{C}$ menghasilkan arang aktif yang mempunyai gugus fungsi $\mathrm{C}-\mathrm{H}$ pada spektrum FT-IR dengan panjang gelombang $871,82 \mathrm{~cm}^{-1}$ dan $958,62 \mathrm{~cm}^{-1}$ yang termasuk kedalam senyawa alkena dengan intensitas yang kuat. Gugus fungsi $\mathrm{C}-\mathrm{H}$ pada spektrum gelombang $1411,89 \mathrm{~cm}^{-1}$ dan $1463,97 \mathrm{~cm}^{-1}$ dengan intensitas yang kuat berupa senyawa alkana. Spektrum FT-IR juga menghasilkan gugus fungsi $\mathrm{C}=\mathrm{C}$ dengan spektrum gelombang pada $1654,92 \mathrm{~cm}^{-1}$ dan gugus fungsi $\mathrm{O}$ - H masing - masing pada gelombang 2007,9 $\mathrm{cm}^{-1}$, $2218,14 \mathrm{~cm}^{-1}$ dan $3309,85 \mathrm{~cm}^{-1}$. Hasil FT-IR untuk arang aktif yang diaktivasi pada suhu $600^{\circ} \mathrm{C}$ di perlihatkan pada Gambar 3.

Arang aktif yang diaktivasi pada suhu $700^{\circ}$ C menunjukkan perubahan spektrum FT-IR jika dibandingkan dengan spektrum pada arang sebelum diaktivasi, tetapi mempunyai jenis gugus fungsi yang sama dengan arang yang diaktivasi pada suhu $500^{\circ} \mathrm{C}$ dan $600^{\circ} \mathrm{C}$. Gugus fungsi yang dihasilkan pada arang yang diaktivasi pada suhu $700^{\circ} \mathrm{C}$ adalah gugus fungsi $\mathrm{C}-\mathrm{H}$ dalam senyawa alkana dan alkena dengan instensitas yang kuat pada spektrum gelombang $873,75 \mathrm{~cm}^{-1}, 960,55 \mathrm{~cm}^{-1}, 1411,89 \mathrm{~cm}^{-1}$ dan1463,97 $\mathrm{cm}^{-1}$. Spektrum juga menghasilkan gugus fungsi $\mathrm{C}$ $=\mathrm{C}$ pada gelombang $1654,92 \mathrm{~cm}^{-1}$. Pada gelombang $2009,63 \mathrm{~cm}^{-1}, 2193,06 \mathrm{~cm}^{-1}$ dan $3309,85 \mathrm{~cm}^{-1}$ gugus fungsi yang dihasilkan adalah gugus $\mathrm{O}-\mathrm{H}$ dengan intensitas yang kuat. Hasil FT-IR untuk arang aktif yang diaktivasi pada suhu $500^{\circ} \mathrm{C}$ di perlihatkan pada Gambar 4.

\section{Kesimpulan}

Tulang merupakan salah satu limbah yang dapat mencemari lingkungan apabila tidak diolah dengan baik. Metode pengolahan yang murah dan ramah lingkungan salah satunya adalah mengolah limbah tulang menjadi produk yang bermanfaat dan benilai jual yaitu arang aktif. Suhu aktivasi terbaik untuk mengolah limbah tulang kambing menjadi arang aktif adalah pada suhu $500{ }^{\circ} \mathrm{C}$ dengan gugus fungsi yang dihasilkan adalah senyawa alkana, alkena, asam karboksilat dan alkohol.

\section{Ucapan Terima Kasih}

Penelitian ini sepenuhnya didanai oleh Kemenristekdikti melalui Direktorat Riset dan Pengabdian Masyarakat pada skim Penelitian Dosen Pemula Anggaran 2019 dan Universitas Abulyatama Aceh Besar yang memberikan dukungan dan fasilitas.

\section{Daftar Pustaka}

Arsad, E. (2017). Teknologi Pengolahan Dan Pemanfaatan Karbon Aktif Untuk Industri. Jurnal Riset Industri Hasil Hutan. https://doi. org/10.24111/jrihh.v2i2.1146

Arsad, E., \& Hamdi, S. (2010). Teknologi pengolahan dan pemanfaatan karbon aktif untuk industri. Jurnal Riset Hasil Industri Hutan.

Chand, Bansal, Roop, Meenakshi Goyal, 2005. Activated Carbon Adsorpsion. United States of America (USA); Lewis Publisher

Dawlet, A., Talip, D., Mi, H. Y., \& MaLiKeZhaTi. (2013). Removal of Mercury from Aqueous Solution Using Sheep Bone Charcoal. Procedia Environmental Sciences, 18, 800-808. https:// doi.org/10.1016/j.proenv.2013.04.108

E.S. Harsanti, SP., M.Sc; Dr. Asep NugrahaArdiwinata, Ms. (2011). Arang Aktif Meningkatkan Kualitas Lingkungan. Agroinovasi, Badan Litbang Pertanian.

El-Hendawy, A. N. A. (2003). Influence of HNO3 oxidation on the structure and adsorptive properties of corncob-based activated carbon. Carbon. https://doi.org/10.1016/S00086223(03)00029-0

Ghanizadeh, G., Asgari, G., Mohammade, A. M. S., \& Ghaneian, M. T. (2012). Kinetics and isotherm studies of hexavalent chromium adsorption from water using bone charcoal. Fresenius Environmental Bulletin, 21(5 A), 1296-1302.

Hartanto, S., \& Ratnawati. (2010). Pembuatan Karbon 
Aktif dari Tempurung Kelapa Sawit dengan Metode Aktivasi Kimia. Jurnal Sains Materi Indonesia.

Hendra, D. (2007). Pembuatan Arang Aktif Dari Limbah Pembalakan Kayu Puspa Dengan Teknologi Produksi Skala Semi PiloT. Jurnal Penelitian Hasil Hutan.

Juliasti, R., Legowo, A. M., \& Pramono, Y. B. (2015). Pemanfaatan Limbah Tulang Kaki Kambing sebagai Sumber Gelatin dengan Perendaman Menggunakan Asam Klorida. Jurnal Aplikasi Teknologi Pangan. https://doi.org/10.17728/ jatp.2015.01

Meisrilestari, Y., Khomaini, R., \& Wijayanti, H. (2013). Pembuatan Arang Aktif dari Cangkang Kelapa Sawit dengan Aktivasi Secara Fisika, Kimia dan Fisika dan Kimia. Konversi. https:// doi.org/10.20527/K.V2I1.136

Mizwar, A. (2018). Aktivasi Kimia-Fisik Limbah Serutan Rotan Menjadi Karbon Aktif. Jurnal Purifikasi. https://doi.org/10.12962/j25983806. v14.i1.13

Mody, L. (2014). Pembuatan Dan Kegunaan Arang Aktif. Info Teknis EBONI.

Mohammad-Khah, A., \& Ansari, R. (2009). Activated charcoal: Preparation, characterization and applications: A review article. International Journal of ChemTech Research.

Mohammed, A., Aboje, A. A., Auta, M., \& Jibril, M. (2012). A Comparative Analysis and Characterization of Animal Bones as Adsorbent. Pelagia Research Library Advances in Applied Science Research, 3(5), 3089-3096. Retrieved from www.pelagiaresearchlibrary.com

Previanti, P., Sugiani, H., Pratomo, U., \& Sukrido, S. (2017). Daya Serap Dan Karakterisasi Arang Aktif Tulang Sapi Yang Teraktivasi Natrium Karbonat Terhadap Logam Tembaga. Chimica et Natura Acta, 3(2). https://doi.org/10.24198/cna. v3.n2.9182

Siahaan, S., Hutapea, M., \& Hasibuan, R. (2013). Penentuan Kondisi Optimum Suhu Dan Waktu Karbonisasi Pada Pembuatan Arang Dari Sekam PadI. Jurnal Teknik Kimia USU.

Sudrajat, R. (2005). Pembuatan Arang Aktif Dari Kayu Jarak Pagar (Jatropha Curcas L.). Jounal of Forest Product Research. https://doi. org/10.20886/jphh.2005.23.4.299-315

Wardani, S., \& Rosa, E. (2018). Potensi Limbah Tulang Kambing Sebagai Arang Aktif Yang Teraktivasi Asam Sulfat. Jurnal Serambi Engineering, 3(2), 308-315. https://doi.org/10.32672/jse.v3i2.714

Wibowo, S., Syafii, W., \& Pari, G. (2016).
Karakteristik Arang Aktif Tempurung Biji Nyamplung (Calophyllum inophyllum Linn). Jurnal Penelitian Hasil Hutan. https://doi. org/10.20886/jphh.2010.28.1.43-54 